\title{
A Design Science Framework for Designing and Assessing User Experience
}

\author{
Sisira Adikari, Craig McDonald, and John Campbell \\ Faculty of Information Sciences and Engineering, \\ University of Canberra, ACT 2601, Australia \\ \{Sisira.Adikari, Craig. McDonald, John. Campbell\}@canberra.edu . au
}

\begin{abstract}
User Experience is a well recognized factor in design and evaluation of artifacts in Human-Computer Interaction. There are many user experience models reported in the literature to reflect this status. Techniques and instruments for managing user experience are still not sufficient. In this paper, we discuss design science research and important user experience models reported in the literature and propose an integrated design science framework for designing and assessing user experience. We also present the results of an experimental study to validate our proposed framework and the instrument employed.
\end{abstract}

Keywords: Design Science, User Experience.

\section{Introduction}

User Experience (UX) aims at gaining a more comprehensive understanding of users interactive experiences with products or systems around new concepts like pleasure [1], fun [2], aesthetics [3] and hedonic qualities 4]. Norman [5] describes the UX as encompassing all aspects of users interaction with a product. The distinction between usability and user experience has been recognised, for example, even a product with good usability can generate negative use experiences causing dissatisfaction while a product with bad usability can generate positive experiences or satisfaction [6], and while bad usability can break a good product, good usability is insufficient to create a good experience [7. Accordingly, the good usability does not guarantee good UX, and it depends on the total interactive experience of a user with a product or system in meeting user needs and expectations. Although, there is no universal definition of user experience [7, the concept of UX has been widely adapted in many areas of design without it being clearly defined or deeply understood [89]. However, there are many views of user experience from the literature. According to Forlizzi and Battarbee, user experience is associated with a wide variety of meanings without cohesive theory of experience for the design community [10. Hassenzahl and Tractinsky see user experience as ranging from traditional usability to beauty, hedonic, affective or experiential aspects of technology use [11. 
A newer ISO standard [12] defines the UX as a persons perceptions and responses that result from the use or anticipated use of a product, system or service emphasizing two main aspects: use and anticipated use. This definition matches the description of experience given by McCarthy and Wright [13. Moreover, the results of a recent research study show that ISO definition of user experience is in line with the view by most respondents about the subjectivity of UX [9]. ISO standard also points out that user experience includes all the users' emotions, beliefs, preferences, perceptions, physical and psychological responses, behaviors and accomplishments that occur before, during and after use and Usability criteria can be used to assess aspects of user experience [12]. UX assessment is an evaluation of the users interactive experience of a product, system or service. Accordingly, use (i.e., actual interaction experience), anticipated use (i.e., pre-interaction experience such as needs and expectations), and after use (postinteraction experience) is equally important for consideration in UX assessments. We consider that total UX consists of these three views and it is shown as a model in Figure 1.

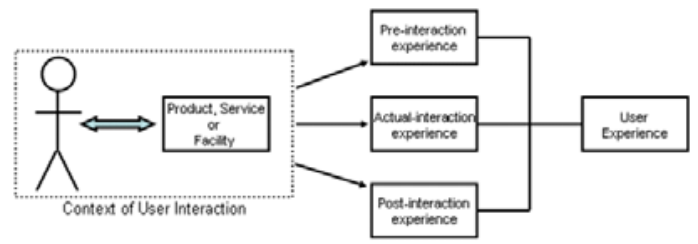

Fig. 1. Total user experience model

In this paper, we briefly discuss important user experience models reported in the literature and propose an enhanced usability model integrated with design science research framework for user experience design and assessment. We also present the results of an experimental study to validate our proposed model and the instrument employed.

\section{Design Science Research}

Design Science (DS) is a research paradigm [14, [15, , 16] which aims at creating and evaluating innovative artifacts that address important and relevant organizational problems. The design science involves the purpose driven creation of artifacts and the introduction of these artifacts into a natural setting [15. The main focus of design science research is to create and evaluate new and improved IT artifacts as a solution for relevant organisational problems and to generate new knowledge to the body of the scientific evidence. Hevner has presented a detailed process of performing design science research by means of three design science research cycles [17. Figure 2 show the existence of three design science research cycles in information systems research framework reported in [18. According to [16], these three research cycles must be present and clearly identifiable in any design science research project. 


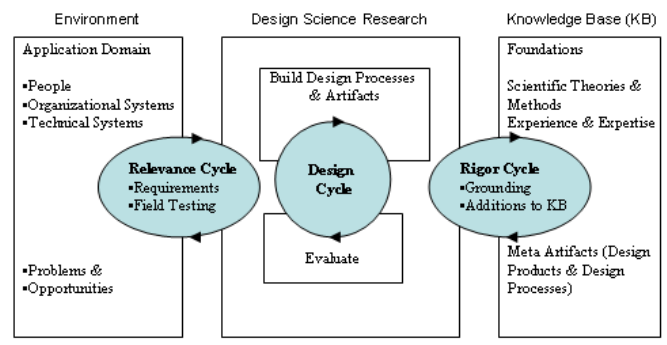

Fig. 2. Design science research cycles

The relevance cycle captures the problem to be addressed and connects the contextual Environment with Design Science Research activities. Thus, the relevance cycle provides the requirements for the research (problems and opportunities) as inputs. It also defines the acceptance criteria for design solutions and artifacts which feed back as outputs from Design Science Research to the Environment for implementation. The suitability of artifacts in Environment is assessed by field testing to determine whether additional iteration of the relevance cycle are needed.

As shown in Figure 2, the Knowledge Base consists of foundations, scientific theories and methods, experience and expertise and meta-artifacts. The rigor cycle connects the Design Science Research activities with the Knowledge Base to receive foundations for rigorous design science research to ensure its innovation. Moreover, the rigor cycle feedbacks new knowledge to the Knowledge Base to update and enrich it. The internal design cycle is central to the Design Science Research where the hard part of the actual design science research is carried out. Inputs to the Design Science Research are: requirements from the relevance cycle and the design and evaluation theories and methods which are drawn from the rigor cycle. The design cycle iterates between the core activities of building and evaluating the design artifacts to generate design alternatives and evaluating the alternatives rigorously and thoroughly against requirements until a satisfactory design is achieved. Finally, design artifacts and research contributions are output into the relevance cycle for implementation in Environment and field evaluations, and to updating the Knowledge Base respectively.

Design Science and Human-Computer Interaction share two important common grounds: design and evaluation. User experience design and evaluation is concerned with building HCI artifacts for contextual requirements and evaluating those against pre-specified assessment criteria. In practical terms, HCI artifact creation and evaluation follow an iterative approach similar to that explained in Design Science Research. Accordingly, we propose that the DSR framework shown in Figure 2 is a well suited framework that can be applied for designing for UX and UX assessment. Our proposed framework is shown in Figure 3 where the user interaction with a system in context is emphasized with 'UX Theories', 'Experimental Designs' and 'Evaluation Artifacts' included in the Knowledge Base. 


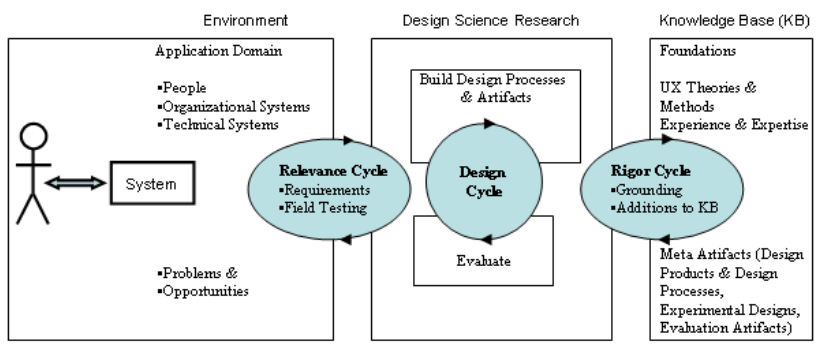

Fig. 3. Proposed design science research framework for designing for user experience and user experience assessment

\section{User Experience Models}

There are many user experience models reported in the literature explaining the aspects of user experience. Many of these models recognize the significance of usability on user experience. Specifically, these models seek to complement a purely functional analysis of user interaction with an account of the sensual, emotional, social and cultural aspects of peoples' relationships with technology [19].

In the context of interaction design, Preece, Rogers and Sharp [20] pointed out the difference between user experience goals and usability goals emphasizing that UX goals are more concerned with how users experience an interactive system from user perspective rather than assessing how useful or productive a system is from product perspective.Their model consists of six usability goals namely: efficient to use, effective to use, safe to use, having good utility, easy to learn, and easy to remember. They defined user experience goals as: satisfying, enjoyable, fun, entertaining, helpful, motivating, aesthetically pleasing, supportive of creativity, rewarding and emotionally fulfilling. According to them, usability goals are fundamental to the user experience and occurs as a result of achieving usability goals during an interaction. Importantly, the model does not include 'satisfaction' as a usability goal; instead, it considers as a UX goal. Taking this view further, Sharp, Rogers and Preece [21, p.26] described an enhanced version of UX goals that included additional positive as well as negative goals, namely: engaging, pleasurable, exciting, cognitively stimulating, provocation, surprising, challenging, enhancing sociability, boring, frustrating, annoying and cutesy. They described many of these goals as subjective qualities concerned with how a system feels to a user. They also highlighted that not all usability and UX goals will be relevant to the design and evaluation of an interactive product (or system) as some combinations will not be compatible.

According to Hassenzahl [22, the origins of UX can be seen from two different views: pragmatic quality and hedonic quality. Hassenzahl argues that the fulfilment of be-goals is the driver of experience, and that pragmatic quality facilitates the potential fulfilment of be-goals. Moreover, Hassenzahl [22] emphasizes that UX is an evaluative feeling of the user while interacting with a product with a shift of the attention from the product to feelings such as subjective side of product use. Another model [1] sees UX as a combination of three 
perspectives: beyond the instrumental, emotion and affect, and experiential and considers as a consequence of the user's internal state, the characteristics of the designed system and the context within which the interaction occurs. Having discussed models and theories of experience, Forlizzi and Battarbee 10] state that experience in interactive systems can be examined and modeled from three perspectives, namely: product-centered, user-centered, and interaction-centered. The definition of UX given by Hassenzahl and Tractinsky [11] also includes user perspective, product perspective and context of interaction perspective. Accordingly, UX is a mixture of these three perspectives: product-centred, user-centred and interaction-centred.

In a recent publication, Bevan 23 highlighted that how product attributes relate different aspects of UX. According to Bevan, direct measurement of actual experience of usage is difficult; the measurable consequences are the user performance, satisfaction with achieving pragmatic and hedonic goals, comfort and pleasure. User performance and satisfaction is determined by quality characteristics such as attractiveness, functional suitability, ease of use, learnability, accessibility and safety. Table 1 presents Bevan's view on how the measures of usability and UX are dependent on the product attributes that support different aspects of UX [23]. Moreover, Bevan points out that the measures of UX consequences can be represented by means of satisfaction in use, with a specific focus on pleasure, likeability and trust. According to Table 1, 'Pleasure' relates to Aesthetics, 'Likability and Comfort' relates to Appropriate Functions, Good UI Design, Learnability and Technical Accessibility and 'Trust' relates to Safe and secure Design.

Petrie and BevanBevan [24] have acknowledged that users of new technologies are not necessarily seeking just to complete a useful task, but also to amuse and entertain themselves. Accordingly, Petrie and Bevan consider that UX, as a concept, emerged to cover the components of users' interactions with, and reactions to, electronic systems that go beyond usability. Table 1 also shows that

Table 1. Factors contributing to UX consequences

\begin{tabular}{|c|c|c|c|c|c|c|}
\hline $\begin{array}{c}\text { Quality } \\
\text { characteristic }\end{array}$ & $\mathrm{ux}$ & Functionality & $\begin{array}{l}\text { User interface } \\
\text { usability }\end{array}$ & Learnability & Accessibility & Safety \\
\hline $\begin{array}{l}\text { Product } \\
\text { attributes }\end{array}$ & $\begin{array}{l}\text { Aesthetic } \\
\text { attributes }\end{array}$ & $\begin{array}{l}\text { Appropriate } \\
\text { functions }\end{array}$ & $\begin{array}{l}\text { Good UI design } \\
\text { (easy to use) }\end{array}$ & $\begin{array}{l}\text { Learnability } \\
\text { attributes }\end{array}$ & $\begin{array}{c}\text { Technical } \\
\text { accessibility }\end{array}$ & $\begin{array}{l}\text { Safe and secure } \\
\text { design }\end{array}$ \\
\hline $\begin{array}{l}\text { UX pragmat- } \\
\text { ic do goals }\end{array}$ & \multicolumn{6}{|c|}{ To be effective and efficient } \\
\hline $\begin{array}{l}\text { UX hedonic } \\
\text { be goals }\end{array}$ & \multicolumn{6}{|c|}{ Stimulation, identification and evocation } \\
\hline $\begin{array}{l}\text { UX: actual } \\
\text { experience }\end{array}$ & Visceral & \multicolumn{5}{|c|}{ Experience of interaction } \\
\hline $\begin{array}{l}\text { Usability (= } \\
\text { performance } \\
\text { in use } \\
\text { measures) }\end{array}$ & \multicolumn{3}{|c|}{$\begin{array}{c}\text { Effectiveness and Productivity } \\
\text { in use: } \\
\text { effective task completion and efficient use of time }\end{array}$} & $\begin{array}{l}\text { Learnability } \\
\text { in use: } \\
\text { effective and } \\
\text { efficient to } \\
\text { learn }\end{array}$ & $\begin{array}{l}\text { Accessibility } \\
\text { in use: } \\
\text { effective and } \\
\text { efficient with } \\
\text { disabilities }\end{array}$ & $\begin{array}{l}\text { Safety } \\
\text { in use: } \\
\text { occurrence of } \\
\text { unintended } \\
\text { consequences }\end{array}$ \\
\hline \multirow{2}{*}{$\begin{array}{l}\text { Measures of } \\
\text { UX } \\
\text { consequences }\end{array}$} & \multicolumn{6}{|c|}{$\begin{array}{l}\text { Satisfaction in use: } \\
\text { satisfaction with achieving pragmatic and hedonic goals }\end{array}$} \\
\hline & Pleasure & \multicolumn{4}{|c|}{ Likability and Comfort } & Trust \\
\hline
\end{tabular}


UX and usability are not two distinct concepts, but have interrelated aspects that contribute equally to providing the overall UX and usability of a system.

\section{Extending Usability for User Experience Assessment}

There are many definitions of usability by different authors such as 25 26 27] etc., where satisfaction is a commonly shared viewpoint. In their study, Lindgaard and Dudek 28] highlight that UX consists in some sense of satisfaction, and emphasize that aesthetics, emotion, expectation, likeability and usability all influence the interactive experience. In a recent research study reported 34 that user satisfaction received the highest agreement as a criterion of UX. Therefore, an enhanced usability model with more focus on satisfaction can be used to probe the satisfaction usability attribute in more depth to explored in identifying how the user feels about the interaction with a product, system or service. For UX assessments, we propose a usability model consisting of eight usability attributes: satisfaction, functional correctness, efficiency, error tolerance, memorability, flexibility, learnability and safety. This is an enhancement of the previous model presented 29, with an additional inclusion of the safety usability attribute. Our proposed usability model is shown in Figure 4 and it serves as an extension to Bevan's view on UX shown in Table 1, In our proposed usability model, we have not considered Technical Accessibility (TA) as a usability attribute and intend to study TA in more detail to determine its impact on usability and UX.

\section{$5 \quad$ User Experience Experiment}

As discussed, the satisfaction attribute can be used beyond aesthetics and conventional satisfaction to provide a broad view of experience on satisfaction in use in

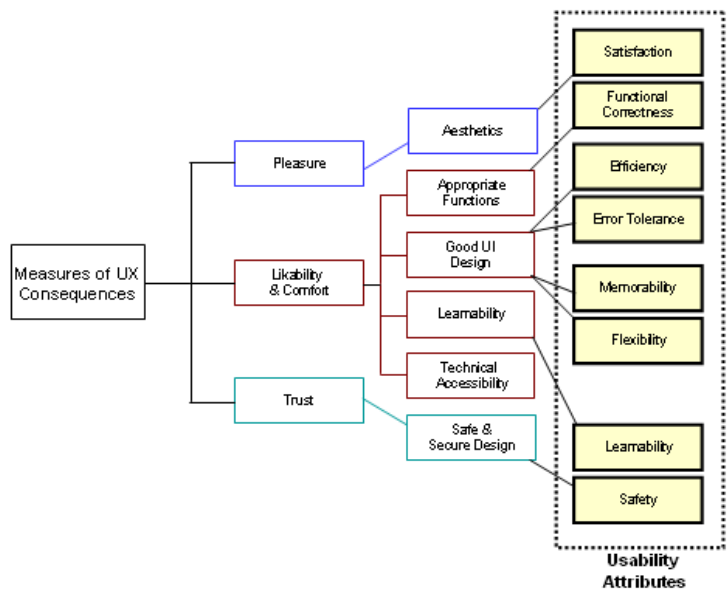

Fig. 4. Proposed usability model 
achieving pragmatic and hedonic goals. This section details how we derived assessment criteria for the satisfaction usability attribute. There are many definitions for the term aesthetics, such as visual appeal [28, beauty in appearance 30, etc. A common viewpoint of these definitions is that aesthetics is related to pleasure and harmony, which human beings are capable of experiencing [30. Accordingly, we consider Visual appeal and Pleasure in interaction as our first two assessment criteria. ISO view on UX shows that Expectations contribute to the UX; hence we chose Meeting expectations as our third assessment criterion. According to Ketola and Roto [31] , Frustration is a measure that could be used to assess UX obstacles in an interaction; therefore, Less frustration has been selected as an assessment criterion. Confusion or lack of understanding is considered as impacting on creating an overall positive user experience [33], hence we have included Less confusing terminology as an assessment criterion. Lastly, the assessment criterion Overall experience of using the system was included to receive a subjective opinion from the user on the overall experience of interaction.

First column of Table 2 shows the complete list of assessment criteria for each usability attributes in our proposed usability model shown in Figure 4. Particularly, the 'Satisfaction' usability attribute examines six UX aspects: visual appeal, pleasure in interaction, meeting expectations, less frustration, less confusing terminology, and overall experience of using the system.

\subsection{Experimental Study}

An evaluation questionnaire consists of 27 questions was developed based on the assessment criteria shown in first column of Table I. The experimental study was carried out in two separate phases. In the first phase, we choose a library information system as the Reference System and conducted a user experience assessment using the evaluation questionnaire with a group of 16 subjects (group G1). We deployed the design science research framework (see Figure 3) as the basis for the second phase of the project. At the beginning, an overview of the design science research framework was given to a team of two developers, and one user experience designer emphasizing the intent of the second phase of the experimental study, and the importance of the relevance and rigor aspects of the design science research framework. The first author acted as an observer to make sure that the team would carry out tasks as intended. For system design, the functional requirements of the Reference System were given to the team along with user experience assessment criteria. The team was then asked to develop new IT artifacts based on functional requirements and user experience assessment criteria through three research cycle approach specified in the design science research framework. Finally, the resulting system (Developed System) was subjected to a user experience evaluation with a different group of 16 subjects (group G2) using the same evaluation questionnaire.

\subsection{Results}

For both systems, user responses for the evaluation questionnaire were collected from both groups of subjects (G1 and G2). These data were statistically 
Table 2. Results

\begin{tabular}{|c|c|c|c|c|c|}
\hline \multirow[b]{2}{*}{ UX Assessment Criterion } & \multicolumn{2}{|c|}{ Reference System } & \multicolumn{2}{|c|}{ Developed System } & \multirow[b]{2}{*}{$\begin{array}{c}\text { Significance } \\
\text { (2-tailed) }\end{array}$} \\
\hline & $\begin{array}{l}\text { Total } \\
\text { Mean }\end{array}$ & $\begin{array}{c}\text { Sto. } \\
\text { Deviation }\end{array}$ & $\begin{array}{l}\text { Total } \\
\text { Mean }\end{array}$ & $\begin{array}{c}\text { Sta. } \\
\text { Deviation }\end{array}$ & \\
\hline Visual appeal & 1.8750 & 1.0247 & 4 & 1.09545 & 0.000 \\
\hline Pleasure in interaction & 2.1875 & 1.10868 & 3.3125 & .60208 & 0.001 \\
\hline Meeting expectations & 2.0625 & .99791 & 3.6875 & .94348 & 0.000 \\
\hline Less frustration & 1.7500 & .77460 & 3.6250 & .88506 & 0.000 \\
\hline Less confusing teminology & 2.2500 & 1.0000 & 3.2500 & .93095 & 0.018 \\
\hline $\begin{array}{l}\text { Overall experience of using the } \\
\text { system }\end{array}$ & 2.1250 & .95743 & 3.1875 & .83417 & 0.008 \\
\hline Completing tasks correctly & 2.0000 & 1.03280 & 3.2500 & .85635 & 0.001 \\
\hline $\begin{array}{l}\text { Awailiable faclities to meet user } \\
\text { needs }\end{array}$ & 2.4375 & .96393 & 3.5000 & .81650 & 0.003 \\
\hline $\begin{array}{l}\text { Available inform ation to make } \\
\text { decisions }\end{array}$ & 1.9375 & .99791 & 3.5625 & 1.03078 & 0.000 \\
\hline Completing tasks quickly & 2.0000 & .73030 & 3.4375 & .81394 & 0.000 \\
\hline Achieving expected outcome & 1.8750 & .71880 & 3.5625 & .89209 & 0.000 \\
\hline Completing tasks e asily & 2.0625 & .99791 & 3.3750 & .80623 & 0.001 \\
\hline Causes fewer errors & 2.0000 & 1.03280 & 3.8125 & .91059 & 0.000 \\
\hline $\begin{array}{l}\text { Clear error messaging for invalid } \\
\text { conditions }\end{array}$ & 1.8125 & 1.04682 & 3.4375 & .81394 & 0.000 \\
\hline $\begin{array}{l}\text { Error messages that inform which } \\
\text { actions to take }\end{array}$ & 1.9875 & .92871 & 3.3750 & .80623 & 0.000 \\
\hline Easiness to remember takk steps & 2.0000 & .73030 & 2.9375 & .85391 & 0.004 \\
\hline Needing to memoise task steps & 2.4375 & .89209 & 3.3750 & .61914 & 0.004 \\
\hline $\begin{array}{l}\text { Needing to access Help } \\
\text { documents }\end{array}$ & 2.4375 & .81394 & 3.5 & .51640 & 0.001 \\
\hline Altern ative ways to perform tasks & 2.1875 & .91059 & \begin{tabular}{|l|l|}
3.1875 \\
\end{tabular} & .75000 & 0.002 \\
\hline $\begin{array}{l}\text { Navigating backfonmard between } \\
\text { task steps }\end{array}$ & 2.1875 & 1.04682 & 3.3750 & .50000 & 0.002 \\
\hline User ability to cancel an operation & 2.1250 & .88506 & 3.5625 & .62915 & 0.000 \\
\hline Ease of learning system operation & 1.8125 & .98107 & 3.5625 & .96393 & 0.000 \\
\hline Clarity of system status & 2.0000 & .73030 & 3.8125 & .83417 & 0.000 \\
\hline Knowing to do next during navig. & 1.8125 & .7500 & 3.9375 & .92871 & 0.000 \\
\hline Fewer keystrokes & 1.8125 & .7500 & 3.9375 & .92871 & 0.000 \\
\hline $\begin{array}{l}\text { Sec. measures to protect } \\
\text { personal info. }\end{array}$ & 1.8125 & .7500 & 3.9375 & .92871 & 0.000 \\
\hline $\begin{array}{l}\text { Sec. measures to protect user } \\
\text { transactions }\end{array}$ & 1.8125 & .7500 & 3.9375 & .92871 & 0.000 \\
\hline
\end{tabular}

analyzed by means of independent samples $\mathrm{T}$ test to measure the significance of user perception for each assessment criterion over two systems. The aim was to determine if there was a significant difference of agreement of user responses for each assessment criterion over reference system and developed system. Table 2 shows the mean response values and respective standard deviations for each criterion over two systems and the resulting 2-tailed significance measure for each criterion.

According to Table 2, for each criterion except criterion 5, there is a significant difference of agreement from users for the Developed System with an associated higher level of mean value $(>3)$. Even for the criterion 5 , the mean value of developed system is $>3$ (where as the mean value of the Reference System $<3$ ). This clearly shows that developed system has been rated as significantly better than reference system in terms of 27 UX assessment criteria.

\section{Conclusions}

In this paper, we have presented a number of approaches to UX modeling and derived a well-grounded assessment criteria that can be used for design for UX as well as conduct an effective UX assessment in HCI. We also presented an integrated approach based on design science research framework for design and assess UX. The main objective of the experimental study was to validate the integrated design science research framework for UX design and assessment. 
The results of the experimental study clearly demonstrate that the integrated design science research framework was successful in generating positive results that highlighted the system differences.

\section{References}

1. Jordan, P.: The Grid: Designing Pleasurable Products: An Introduction to New Human Factors. Taylor \& Francis, Abington (2000)

2. Blythe, M., Overbeeke, K., Monk, A., Wright, P.: Funology: from usability to enjoyment. Kluwer Academic Publishers, Dordrecht (2003)

3. Tractinsky, N., Katz, A.S., Ikar, D.: What is beautiful is usable. Interacting with Computers 13, 127-145 (2000)

4. Hassenzahl, M.: The interplay of beauty, goodness, and usability in interactive products. Human-Computer Interaction 19, 319-349 (2004)

5. Norman, D.: The invisible computer: Why good products can fail, the personal computer is so complex, and information appliances are the answer. The MIT Press, Cambridge (1998)

6. Jokela, T.: When good things happen to bad products: where are the benefits of usability in the consumer appliance market? Interactions 11, 28-35 (2004)

7. Kuniavsky, M.: Smart Things: Ubiquitous Computing User Experience Design. Morgan Kaufmann, San Francisco (2010)

8. Law, E., Roto, V., Vermeeren, A., Kort, J., Hassenzahl, M.: Towards a shared definition of user experience. In: CHI, pp. 2395-2398 (2008)

9. Law, E., Roto, V., Hassenzahl, M., Vermeeren, A., Kort, J.: Understanding, scoping and defining user experience: a survey approach. In: CHI, Boston, pp. 719-728 (2009)

10. Forlizzi, J., Battarbee, K.: Understanding experience in interactive systems. In: DIS 2004, Proceedings of the 5th Conference on Designing Interactive Systems: Processes, Practices, Methods, and Techniques, pp. 261-268 (2004)

11. Hassenzahl, M., Tractinsky, N.: User experience-a research agenda. Behaviour and Information Technology 25, 91-97 (2006)

12. ISO FDIS 9241-210: Human-centred design process for interactive systems. ISO (2009)

13. McCarthy, J., Wright, P.: Technology as experience. Interactions 11, 42-43 (2004)

14. Iivari, J.: A paradigmatic analysis of information systems as a design science. Scandinavian Journal of Information Systems 19, 39-63 (2007)

15. Baskerville, R.: What design science is not. European Journal of Information Systems 17, 441-443 (2008)

16. Hevner, A., Chatterjee, S.: Design science research in information systems - Theory and Practice. Springer, Heidelberg (2010)

17. Hevner, A.: The Three Cycle View of Design Science Research. Scandinavian Journal of Information Systems 19, 87-92 (2007)

18. Hevner, A.R., March, S.T., Park, J., Ram, S.: Design science in information systems research. MIS Quarterly 28, 75-105 (2004)

19. Blythe, M.A., Wright, P.C.: Pastiche scenarios: Fiction as a resource for user centred design. Interacting with Computers 18, 1139-1164 (2006)

20. Preece, J., Rogers, Y., Sharp, H.: Interaction design: beyond human-computer interaction. Wiley, Chichester (2002) 
21. Sharp, H., Rogers, Y., Preece, J.: Interaction design: beyond human-computer interaction. Wiley, Chichester (2007)

22. Hassenzahl, M.: User experience (UX): towards an experiential perspective on product quality. In: Proceedings of the 20th International Conference of the Association Francophone d'Interaction Homme-Machine, pp. 11-15 (2008)

23. Bevan, N.: Classifying and selecting UX and usability measures. In: International Workshop on Meaningful Measures: Valid Useful User Experience Measurement, pp. $13-18$ (2008)

24. Petrie, H., Bevan, N.: The evaluation of accessibility, usability and user experience. In: Stephanidis, C. (ed.) The Universal Access Handbook, pp. 20.1-20.14. CRC Press, Boca Raton (2009)

25. Nielsen, N.: The usability engineering. Academic Press, San Diego (1993)

26. Shneiderman, B.: Designing the user interface: strategies for effective humancomputer interaction. Addison Wesley Longman, Boston (1998)

27. Dix, A., Finlay, J., Abowd, G.D.: Human-computer interaction. Prentice-Hall, Upper Saddle River (2004)

28. Lindgaard, G., Dudek, C.: What is this evasive beast we call user satisfaction. Interacting with Computers 15, 429-452 (2003)

29. Adikari, S., McDonald, C., Lynch, N.: Design science-oriented usability modelling for software requirements. In: 12th International Conference on Human-Computer Interaction: Interaction Design and Usability, pp. 373-382 (2007)

30. Lindgaard, L.: Aesthetics, visual appeal, usability, and user satisfaction: What do the user's eyes tell the user's brain 5, 429-452 (2007)

31. Lavie, T., Tractinsky, N.: Assessing dimensions of perceived visual aesthetics of web sites. International Journal of Human-Computer Studies 60, 269-298 (2004)

32. Ketola, P., Roto, V.: Exploring user experience measurement needs. In: 5th COST294-MAUSE Open Workshop on Valid Useful User Experience Measurement, VUUM (2008)

33. Tullis, T., Albert, W.: Measuring The User Experience: collecting, analyzing, and presenting usability metrics. Morgan Kaufmann, San Francisco (2008)

34. Naumann, A.B., Wechsung, I., Schleicher, R.: Measurements and concepts of usability and user experience: Differences between industry and academia. In: Kurosu, M. (ed.) HCD 2009. LNCS, vol. 5619, pp. 618-626. Springer, Heidelberg (2009) 